\title{
Fuzzy Matrix for Ebola Virus Disease in Human Body
}

\author{
T. Geetha $+*$ and A. Usha ** \\ +* Department Of Mathematics, K.N. Govt Arts College ( Woman), Thanjavur, Tamil Nadu, India. \\ ** Research Scholar Department Of Mathematics, K. N. Govt Arts College (Woman), Thanjavur, Tamil \\ Nadu, India.
}

\begin{abstract}
The aim of this paper is to design a Fuzzy soft matrix for Ebola virus disease diagnosis, by using the notion of fuzzy soft matrices. We apply fuzzy soft set technology through the well known Sanchez's approach for HUMAN BODY DISEASE diagnosis. Further, we extended our approach in the sector of addition and multiplication factors of fuzzy soft matrices based on reference function. Sanchez's formulated the diagnostic models involving fuzzy matrices representing the medical knowledge between the symptoms and diseases.

Keywords: Fuzzy soft set, fuzzy soft matrices, Max product composition of fuzzy soft matrix, Ebola virus disease.
\end{abstract}

\section{INTRODUCTION}

The field of medicine is one of the most fruitful and interesting areas of applications for fuzzy set theory. The theory of soft sets has rich potential for applications in several directions, few of which had been demonstrated by Molodtsov in his original work. At present, works on soft set theory are making progress quickly. Maji et al initiated the concept of fuzzy soft sets with some properties regarding fuzzy soft union, intersection, complement of a fuzzy soft set, De Morgan's Law etc. Neog and Sut have reintroduced the notion of fuzzy soft sets and redefined the complement of a fuzzy soft set accordingly. They have shown that the modified definition of complement of a fuzzy soft set meets all the requirements that complement of a set in classical sense really does. Applications of Fuzzy Soft Set Theory in many department and real life situations have been studied by many researchers. In this paper, by using the notion of fuzzy soft matrices, we apply fuzzy soft set technology through the well known Sanchez's approach for medical diagnosis and we exhibit the technique with Ebola virus disease case study.

Ebola virus disease is one of the most deathly ailments known to mankind due to its high death rate (up to $90 \%$ ) convoying with the disease. Ebola haemorrhagic fever (EHF) is an infectious disease of animal that can be transmitted to both human and non-human primates. The first epidemic of EHF occurred in 1976 in the Democratic Republic of the Congo. The incubation period of Ebola is less than 21 days. Ebola virus infections are depicted by immune suppression and a systemic inflammatory response that leads to damage of the vascular, coagulation and immune systems, causing multi-organ failure and shock. Five genetically distinct members of the Filoviridae family responsible for EHF are as follows: Zaire ebolavirus, Sudan ebolavirus, Côte d'Ivoire ebolavirus, Bundibugyo ebolavirus and Reston ebolavirus. The ongoing 2016 West Africa Ebola epidemic has been considered as the most serious panic in the medical field with respect to both the number of human cases and death toll. The natural host for Ebola virus is unknown, thus it is not possible to carry out programs to control or destroy virus from transmission to people. The Ebola virus infection provides little chance to develop acquired immunity causing rapid progression of the disease. It is pertinent to mention that at present, there is no antiviral therapy or vaccine that is helpful against Ebola virus infection in humans. The present review is an attempt to summarize various essential aspects of EVD or EHF.

\section{PRELIMINARIES}

In this section, we recall some basic essential notion of fuzzy soft set and defined different types of fuzzy soft set.

\subsection{Soft set}

Let $U$ be an initial universe set and $E$ be a set of parameters. Let $\mathrm{P}(\mathrm{U})$ denotes the power set of $\mathrm{U}$. Let $\mathrm{A} \subseteq \mathrm{E}$.

A pair $\left(F_{A}, E\right)$ is called a soft set over $U$, where $F_{A}$ is a mapping given by $\mathrm{F}_{\mathrm{A}}: \mathrm{E} \rightarrow \mathrm{P}(\mathrm{U})$ such that $\mathrm{F}_{\mathrm{A}}(\mathrm{e})=\varphi$ if $\mathrm{e} \notin \mathrm{A}$. 
Here $F_{A}$ is called approximate function of the soft set $\left(F_{A}, E\right)$. The set $F_{A}(e)$ is called eapproximate value set which consist of related objects of the parameter $e \epsilon E$. In other words, a soft set over $U$ is a parameterized family of subsets of the universe $\mathrm{U}$.

\subsection{Fuzzy soft set}

Let $\mathrm{U}$ be an initial universe set and $\mathrm{E}$ be a set of parameters. Let $\mathrm{A} \subseteq \mathrm{E}$. A pair $\left(\mathrm{F}_{\mathrm{A}}, \mathrm{E}\right)$ is called a fuzzy soft set (FSS)over $U$, where $F_{A}{ }^{\sim}$ is a mapping given by, $\mathrm{F}_{\mathrm{A}}{ }^{2}: \mathrm{E} \rightarrow \mathrm{I}^{\mathrm{U}}$, where $\mathrm{I}^{\mathrm{U}}$ denotes the collection of all fuzzy subsets of $U$.

\subsection{Fuzzy soft class}

Let $\mathrm{U}$ be an initial universe set and $\mathrm{E}$ be the set of attributes. Then the pair (U, E) denotes the collection of all fuzzy soft sets on $U$ with attributes from $\mathrm{E}$ and is called a fuzzy soft class.

\subsection{Fuzzy soft subset}

For two fuzzy soft sets $\left(\mathrm{F}_{\mathrm{A}}^{\sim}, \mathrm{E}\right)$ and $\left(\mathrm{G}_{\mathrm{B}}^{\sim}, \mathrm{E}\right)$ over a common universe $\mathrm{U}$, we have $\left(\mathrm{F}_{\mathrm{A}}{ }^{\sim}, \mathrm{E}\right)$ $\subseteq\left(\mathrm{G}_{\mathrm{B}}{ }^{\tilde{}}, \mathrm{E}\right)$ if $\mathrm{A} \subset \mathrm{B}$ and $\forall \mathrm{e} \in \mathrm{A}, \mathrm{F}_{\mathrm{A}}^{\sim}$,(e) is a fuzzy subset of $\mathrm{G}_{\mathrm{B}}{ }^{\sim}$ (e). i.e, $\left(\mathrm{F}_{\mathrm{A}}, \mathrm{E}\right)$ is a fuzzy soft subset of $\left(\mathrm{G}_{\mathrm{B}}^{\sim}, \mathrm{E}\right)$.

\subsection{Fuzzy soft complement set}

The complement of fuzzy soft set $\left(\mathrm{F}_{\mathrm{A}} \tilde{}, \mathrm{E}\right)$ denoted by $\left(\mathrm{F}_{\mathrm{A}^{\sim}}{ }^{\circ}, \mathrm{E}\right){ }^{\circ}$ is defined by $\left(\mathrm{F}_{\mathrm{A}}{ }^{\sim}, \mathrm{E}\right){ }^{\circ}=\left(\mathrm{F}_{\mathrm{A}}\right.$ ,E) where $\mathrm{F}_{\mathrm{A}}{ }^{\circ}: \mathrm{E} \rightarrow \mathrm{I}^{\mathrm{U}}$ is a mapping given by $\mathrm{F}_{\mathrm{A}}^{\tilde{0}}(\mathrm{e})=\left[\mathrm{F}_{\mathrm{A}}^{\tilde{A}}(\mathrm{e})\right]^{\circ}, \forall \mathrm{e} \epsilon \mathrm{E}$.

\section{FUZZY SOFT MATRICES RELIED UPON REFERENCE FUNCTION}

In this section, we introduce the notion of fuzzy soft matrices with different types based on reference function.

\subsection{Fuzzy soft matrices}

Let $U=\left\{\mathrm{u}_{1}, \mathrm{u}_{2}, \ldots . \mathrm{u}_{\mathrm{m}}\right\}$ be the universal set and $\mathrm{E}$ be the set of parameters given by

$\mathrm{E}=\{$

$\left.\mathrm{e}_{1}, \mathrm{e}_{2}, \ldots . . \mathrm{e}_{\mathrm{n}}\right\}$. Then the fuzzy soft set $\left(\mathrm{F}_{\mathrm{A}} \tilde{\mathrm{N}}, \mathrm{E}\right)$ can be expressed in matrix form as $\quad A^{\sim}=\left[a_{i j}{ }^{\sim}\right.$ ] $\mathrm{m} \times \mathrm{n}$ or simply by $\left[\mathrm{a}_{\mathrm{ij}}^{\mathrm{A}^{\sim}}\right], \mathrm{i}=1,2, \ldots, \mathrm{m}$,

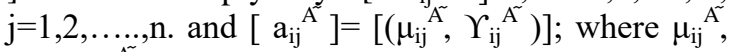
and $\Upsilon_{i j}{ }^{\mathrm{A}}$ represent the fuzzy membership function and fuzzy reference function respectively of $\mathrm{u}_{\mathrm{i}}$ in the fuzzy set $F_{\mathrm{A}}$ (ej) so that $\delta_{\mathrm{ij}}{ }^{\tilde{A^{\tau}}}=\mu_{\mathrm{ij}} \tilde{A}^{\tilde{}}-\Upsilon_{\mathrm{ij}}{ }^{\tilde{A}}$ gives the fuzzy membership value of $u_{i}$. We shall identify a fuzzy soft set with its fuzzy soft matrix and use these two concepts interchangeable. The set of all $m \times n$ fuzzy soft matrices over $U$ will be denoted by FSM $m \times n$. For usual fuzzy sets with fuzzy reference function 0 , it is obvious to see that $\mathrm{a}_{\mathrm{ij}} \mathrm{A}^{\widetilde{2}}=\left[\left(\mu_{\mathrm{ij}}^{\tilde{\mathrm{A}}}, 0\right] \forall \mathrm{i}, \mathrm{j}\right.$.

3.2 Membership Value Matrix

The membership value matrix corresponding to the matrix $\tilde{\mathrm{A}^{-}}$as $\operatorname{MV}(\tilde{\mathrm{A}})=\left[\delta^{\tilde{A}}\right] \mathrm{m} \times \mathrm{n}$, where $\delta_{\mathrm{ij}}^{\tilde{\mathrm{A}^{2}}}$
$=\mu_{\mathrm{ij}}^{\tilde{\mathrm{A}}} \mathrm{Y}_{\mathrm{ij}}^{\mathrm{A}} \mathrm{i}=1,2,3 \ldots . \mathrm{m}$ and $\mathrm{j}=1,2,3, \ldots . \mathrm{n}$, where $\mu_{\mathrm{ij}}^{\mathrm{A}}$, and $\Upsilon_{\mathrm{ij}} \mathrm{A}^{\tilde{2}}$ represent the fuzzy membership function and fuzzy reference function respectively of $\mathrm{u}_{\mathrm{i}}$ in the fuzzy set $\mathrm{F}_{\mathrm{A}}\left(\mathrm{e}_{1}\right)$

3.3 Complement of fuzzy soft matrices

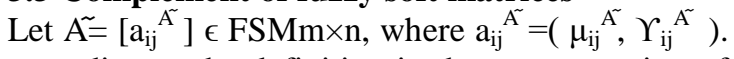
according to the definition in the representation of the complement of the fuzzy matrix $A^{\sim}$ which is denoted by $A^{\sim}$ and then $A^{\sim}$ is called fuzzy soft complement matrix if $\mathrm{A}^{\sim}=\left[\left(1, \mathrm{a}_{\mathrm{ij}} \tilde{\tilde{A}}\right)\right] \mathrm{m} \times \mathrm{n}$ for all $\mathrm{a}_{\mathrm{ij}} \mathrm{A}^{\sim}$ $[0,1]$. Then the matrix obtained from so called membership value would be the following $A^{\sim}=a_{i j}{ }^{\sim}$ $=\left[\left(1-\mathrm{a}_{\mathrm{ij}}{ }^{\tilde{\mathrm{A}}}\right]\right.$ for all $\mathrm{i}$ and $\mathrm{j}$.

\subsection{Max Product of fuzzy soft matrices}

Let $\tilde{A}=\left[a_{i j}^{\tilde{A}}\right] \in$ FSMm $\times n$, where $a_{i j}{ }^{\tilde{A}}=\left(\mu_{i j} \tilde{A}, \Upsilon_{i j}{ }^{\tilde{A}}\right)$ represent the fuzzy membership function and fuzzy reference function of $u_{i}$, so that $\delta_{i j}{ }^{\tilde{A}}=\mu_{i j}{ }^{\tilde{A}}-\Upsilon_{i j}^{A^{\tilde{A}}}$ gives the fuzzy membership value of $u_{i}$.Also let

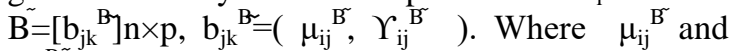
$\Upsilon_{\mathrm{ij}} \mathrm{B}^{\sim}$ represent the fuzzy membership function and fuzzy reference function of $u_{i}$. so that $\delta_{i j}{ }^{A^{\tau}}=\left(\mu_{i j}{ }^{\mathrm{B}^{\tau}}\right.$ $\left.\Upsilon_{i j}{ }^{B}\right)$ gives the fuzzy membership value of $u_{i}$. We now define $A^{\sim} \stackrel{\circ}{\circ}$, the product of $A^{\sim}$ and $B^{\sim}$ as

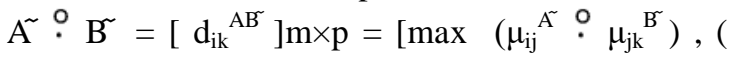
$\left.\max \left(\Upsilon_{\mathrm{ij}}{ }^{\tilde{}} \stackrel{\circ}{O} \Upsilon_{\mathrm{jk}}^{{ }^{\mathrm{B}}}\right)\right] \mathrm{m} \times \mathrm{p}, 1 \leq \mathrm{I} \leq \mathrm{m}, 1 \leq \mathrm{k} \leq \mathrm{p}$ for $\quad \mathrm{j}$ $=1,2,3, \ldots \ldots, \mathrm{n}$.

\section{APPLICATION OF FSM IN HUMAN BODY DISEASE DIAGNOSIS}

In this section, we are put forwarding the problem which is based upon FSM in human body disease diagnosis.

\subsection{Effect Of Ebola Virus Disease In Human Body}

The concept of fuzzy soft matrices is applied to identify the group of human being who are affected to Ebola virus. Real dangers occurred for Ebola virus and there will be weakening of health.

\subsection{Max Product Fuzzy Soft Matrices in Human} body diseases Diagnosis

Let us assume $\mathrm{S}$ is the set of symptoms of some side effects of Ebola virus, D is the side effects related to these symptoms and $\mathrm{P}$ is the set of patients showing the symptoms present in the set $\mathrm{S}$. We construct a fuzzy soft set $\left(\tilde{F_{A}}, D\right)$ over $S$. A relation matrix $A^{\sim}$ is obtained from the fuzzy soft set $\left(\tilde{F}_{A}, D\right)$. We would name the matrix as symptom-disease matrix. Similarly its complement $\left(\tilde{\mathrm{F}}_{\mathrm{A}}, \mathrm{D}\right)^{\circ}$ gives another relation matrix $\mathrm{A}^{\sim}$ called non symptom diseases matrix. We call the matrices $A^{\sim}$ and $\tilde{A}^{\circ}$ as medical $\left(\tilde{F_{B}}, S\right)$ over P. This fuzzy soft set gives the relation matrix $\tilde{B}$ called patientsymptom matrix and its complement $\left(\tilde{\mathrm{F}_{\mathrm{B}}}, \mathrm{S}\right)^{\circ}$ gives the relation matrix $\widetilde{B}^{\circ}$ called patient- non symptom matrix. Then using Definition 3.4 above, we obtain two new relation matrices $\tilde{R}_{1}=\tilde{B}$ : $\tilde{A}$ and

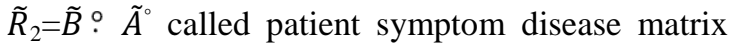


and patient symptom non disease matrix respectively. In a similar manner, we obtain the relation matrices $\widetilde{R}_{3}=\widetilde{B}^{\circ}$. $\tilde{A}$ and $\widetilde{R}_{4}=\widetilde{B}^{\circ}$. $\tilde{A}^{\circ}$ called the patient non symptom disease matrix and patient non symptom non disease matrix respectively. using definition 3.2 we may obtain the corresponding membership value matrices $\operatorname{MV}\left(\tilde{R}_{1}\right), \operatorname{MV}\left(\tilde{R}_{2}\right), \operatorname{MV}\left(\tilde{R}_{3}\right)$, and $\operatorname{MV}\left(\tilde{R}_{4}\right)$

We calculate the diagnosis score $\mathrm{S} \tilde{T}_{1}$ and $\mathrm{S} \tilde{T}_{2}$ for and against the disease respectively as

$\mathrm{S} \tilde{R}_{1}=\left[\Upsilon\left(\tilde{R}_{1}\right)_{\mathrm{ij}}\right]_{\mathrm{m} \times \mathrm{n}}$, Where $\Upsilon\left(\tilde{R}_{1}\right)_{\mathrm{ij}}=\delta\left(\tilde{R}_{3}\right)_{\mathrm{ij}}-\delta$ $\left(\tilde{R}_{1}\right)_{\mathrm{ij}}$

$\mathrm{S} \tilde{R}_{2}=\left[\Upsilon\left(\tilde{R}_{2}\right)_{\mathrm{ij}}\right]_{\mathrm{m} \times \mathrm{n}}$, Where $\Upsilon\left(\tilde{R}_{2}\right)_{\mathrm{ij}}=\delta\left(\tilde{R}_{2}\right)_{\mathrm{ij}}-\delta$ $\left(\tilde{R}_{4}\right)_{\mathrm{ij}}$

Now if $\max \left(\mathrm{S} \widetilde{R}_{2}\left(\mathrm{p}_{\mathrm{i}}, \mathrm{d}_{\mathrm{j}}\right)-\mathrm{S} \widetilde{R}_{1}\left(\mathrm{p}_{\mathrm{i}}, \mathrm{d}_{\mathrm{j}}\right)\right)$ occurs for exactly $\left(\mathrm{p}_{\mathrm{i}}, \mathrm{d}_{\mathrm{k}}\right)$ only, then we would be in a position to accept that diagnosis hypothesis for patient pi is the disease $d_{k}$. In case there is a tie, the process is repeated for patient pi by reassessing the symptoms.

\subsection{Algorithm}

1. Input the fuzzy soft set $\left(\tilde{F_{A}}, D\right)$ and compute $\left(\tilde{\mathrm{F}_{\mathrm{A}}}, \mathrm{D}\right)^{\circ}$ Compute the corresponding matrices $\tilde{A}$ and $\tilde{A}^{\circ}$.

2. Input the fuzzy soft set $\left(\tilde{\mathrm{F}_{\mathrm{B}}}, \mathrm{S}\right)$ and compute $\left(\tilde{\mathrm{F}_{\mathrm{B}}}, \mathrm{S}\right)^{\circ}$. Compute the corresponding matrices $\tilde{B}$ and $\tilde{B}^{\circ}$.

3. Compute $\tilde{R}_{1}=\tilde{B} \circ \tilde{A}, \tilde{R}_{2}=\tilde{B}^{\circ} \cdot \tilde{A}^{\circ}, \tilde{R}_{3}=\tilde{B}^{\circ} \circ \tilde{A}$, $\tilde{R}_{4}=\tilde{B}^{\circ}: \tilde{A}^{\circ}$.

4. Compute the corresponding membership value matrices $\operatorname{MV}\left(\tilde{R}_{1}\right), \operatorname{MV}\left(\tilde{R}_{2}\right), \operatorname{MV}\left(\tilde{R}_{3}\right)$, and $\operatorname{MV}\left(\tilde{R}_{4}\right)$

5. Compute the diagnosis score $\mathrm{S} \widetilde{R}_{1}$ and $\mathrm{S} \widetilde{R}_{2}$.

$$
\tilde{A}=\begin{array}{lll}
\mathrm{d}_{1} & \mathrm{~d}_{2} \\
\mathrm{~S}_{1} & \mathrm{~S}_{2} \\
\mathrm{~S}_{3}
\end{array}\left[\begin{array}{ll}
(0.7,0) & (0.6,0) \\
(0.4,0) & (0.7,0) \\
(0.6,0) & (0.8,0)
\end{array}\right]
$$

6. Find $\mathrm{S}_{\mathrm{k}}=\max \left(\mathrm{S} \tilde{R}_{2}\left(\mathrm{p}_{\mathrm{i}}, \mathrm{d}_{\mathrm{j}}\right)-\mathrm{S} \tilde{R}_{1}\left(\mathrm{p}_{\mathrm{i}}, \mathrm{d}_{\mathrm{j}}\right)\right)$.We conclude that the patient $\mathrm{P}_{\mathrm{i}}$ is suffering from the disease $\mathrm{dk}$.

7. If $S_{k}$ has more than one value, then go to step (1) and repeat the process by reassessing the symptoms for the patient.

\subsection{CASE STUDY}

Suppose that there are three patients $\mathrm{P}_{1}, \mathrm{P}_{2}, \mathrm{P}_{3}$ are admitted in a hospital with symptoms of EVD include fever and headache $\left(S_{1}\right)$, fatigue $\left(S_{2}\right)$, sore throat and muscle pain $\left(\mathrm{S}_{3}\right)$. Let the possible diseases relating to the above symptoms be earlier stage of Ebola hemorrhagic fever $(\mathrm{EHF})\left(\mathrm{d}_{1}\right)$ and Advanced stage of Ebola hemorrhagic fever (EHF )$\left(d_{2}\right)$.

SteP1

Let the fuzzy soft set $\left(\tilde{\mathrm{F}_{\mathrm{A}}}, \mathrm{D}\right)$ over $\mathrm{S}$, where $\tilde{F}_{A}$ is a mapping $\tilde{F}_{A}: \mathrm{D} \rightarrow \tilde{F}(S)$, gives an approximate description of fuzzy soft medical knowledge of the side effect diseases and their symptoms appeared due to EVD.

Let $\left(\tilde{F_{A}}, D\right)=\left\{\tilde{F_{A}},\left(d_{1}\right)=\left\{\left(S_{1}, 0.7,0\right),\left(S_{2}, 0.4,0\right)\right.\right.$, $\left.\left(\mathrm{S}_{3}, 0.6,0\right)\right\}$,

$\left.\tilde{\mathrm{F}}_{\mathrm{A}},\left(\mathrm{d}_{2}\right)=\left\{\left(\mathrm{S}_{1}, 0.6,0\right),\left(\mathrm{S}_{2}, 0.7,0\right),\left(\mathrm{S}_{3}, 0.8,0\right)\right\}\right\}$

Complement of $\left(\tilde{\mathrm{F}_{\mathrm{A}}}, \mathrm{D}\right)(\mathrm{i} . \mathrm{e})\left(\tilde{\mathrm{F}_{\mathrm{A}}}, \mathrm{D}\right)^{\circ}$ is given by

$\left(\tilde{\mathrm{F}_{\mathrm{A}}}, \mathrm{D}\right)^{\circ}=\left\{\tilde{\mathrm{F}_{\mathrm{A}}},\left(\mathrm{d}_{1}\right)=\left\{\left(\mathrm{S}_{1}, 1,0.7\right),\left(\mathrm{S}_{2}, 1,0.4\right),\left(\mathrm{S}_{3}\right.\right.\right.$, $1,0.6)\}$,

$\left.\tilde{\mathrm{F}_{\mathrm{A}}},\left(\mathrm{d}_{2}\right)=\left\{\left(\mathrm{S}_{1}, 1,0.6\right),\left(\mathrm{S}_{2}, 1,0.7\right),\left(\mathrm{S}_{3}, 1,0.8\right)\right\}\right\}$

We represent the fuzzy soft sets $\left(\tilde{\mathrm{F}_{\mathrm{A}}}, \mathrm{D}\right)$ and $\left(\tilde{\mathrm{F}_{\mathrm{A}}}, \mathrm{D}\right)^{\circ}$ by the following matrices $\tilde{A}$ and $\tilde{A}^{\circ}$ respectively.

$$
\left.\tilde{A}^{\circ}=\quad \mathrm{S}_{1} \begin{array}{ll}
\mathrm{d}_{1} & \mathrm{~d}_{2} \\
\mathrm{~S}_{2} & \mathrm{~S}_{3}
\end{array} \begin{array}{ll}
(1,0.7) & (1,0.4) \\
(1,0.6) & (1,0.7) \\
&
\end{array}\right)
$$

\section{SteP2}

Again we take $\mathrm{P}=\left(\mathrm{P}_{1}, \mathrm{P}_{2}, \mathrm{P}_{3}\right)$ as the universal set where $\mathrm{P}_{1}, \mathrm{P}_{2}$ and $\mathrm{P}_{3}$ represent three patients respectively and $\mathrm{S}\left\{\mathrm{S}_{1}, \mathrm{~S}_{2}, \mathrm{~S}_{3}\right\}$ as the set of parameters, where $\mathrm{S} 1, \mathrm{~S} 2$ and $\mathrm{S} 3$ represent the symptoms of side effect diseases.

Let $\left(\tilde{F}_{B}, S\right)$ fuzzy soft set, where $\quad \tilde{F}_{B}$ is a mapping $\tilde{F}_{B}: S \rightarrow \tilde{F}(P)$, gives a collection of an approximate description of the patient side effect symptoms in the hospital.

Let $\left(\mathrm{F}_{\mathrm{B}}, \mathrm{S}\right)=\left\{\tilde{\mathrm{F}_{\mathrm{B}}},\left(\mathrm{S}_{1}\right)=\left\{\left(\mathrm{P}_{1}, 0.7,0\right),\left(\mathrm{P}_{2}, 0.9,0\right),\left(\mathrm{P}_{3}, 0.5,0\right)\right\}\right.$,

$\tilde{F_{B}},\left(\mathrm{~S}_{2}\right)=\left\{\left(\mathrm{P}_{1}, 0.7,0\right),\left(\mathrm{P}_{2}, 0.5,0\right),\left(\mathrm{P}_{3}, 0.8,0\right)\right\}$,

$\left.\tilde{F_{B}},\left(\mathrm{~S}_{3}\right)=\left\{\left(\mathrm{P}_{1}, 0.9,0\right),\left(\mathrm{P}_{2}, 0.6,0\right),\left(\mathrm{P}_{3}, 0.7,0\right)\right\}\right\}$

We note this fuzzy soft set $\left(\widetilde{F}_{B}, S\right)$ by the following $\quad \tilde{B}$, called patient symptom matrix. 
Complement of $\left(\tilde{\mathrm{F}_{\mathrm{A}}}, \mathrm{S}\right)$ (i.e) $\left(\tilde{\mathrm{F}_{\mathrm{A}}}, \mathrm{S}\right)^{\circ}$ is given by

Let $\left(\tilde{\mathrm{F}_{\mathrm{A}}}, \mathrm{S}\right)^{\circ}=\left\{\tilde{\mathrm{F}_{\mathrm{B}}},\left(\mathrm{S}_{1}\right)=\left\{\left(\mathrm{P}_{1}, 1,0.7\right),\left(\mathrm{P}_{2}, 1,0.9\right),\left(\mathrm{P}_{3}, 1,0.5\right)\right\}\right.$,

$\tilde{\mathrm{F}_{\mathrm{B}}},\left(\mathrm{S}_{2}\right)=\left\{\left(\mathrm{P}_{1}, 1,0.7\right),\left(\mathrm{P}_{2}, 1,0.5\right),\left(\mathrm{P}_{3}, 1,0.8\right)\right\}$

$\left.\mathrm{F}_{\mathrm{B}},\left(\mathrm{S}_{3}\right)=\left\{\left(\mathrm{P}_{1}, 1,0.9\right),\left(\mathrm{P}_{2}, 1,0.6\right),\left(\mathrm{P}_{3}, 1,0.7\right)\right\}\right\}$

We represent the fuzzy soft sets $\left(\tilde{\mathrm{F}_{\mathrm{A}}}, \mathrm{S}\right)$ and $\left(\tilde{\mathrm{F}_{\mathrm{A}}}, \mathrm{S}^{\circ}\right.$ by the following matrices $\tilde{B}$ and $\tilde{B}^{\circ}$ respectively.

\begin{tabular}{|c|c|c|c|c|c|c|c|c|c|c|}
\hline \multirow{4}{*}{$\tilde{3}=$} & & $S_{1}$ & & \multirow{4}{*}{$\begin{array}{l}\mathrm{S}_{3} \\
(0.5,0) \\
(0.8,0) \\
(0.7,0)\end{array}$} & \multirow{4}{*}{$\tilde{B}^{\circ}$} & & \multirow{3}{*}{$\begin{array}{l}\mathrm{P}_{1} \\
\mathrm{P}_{2}\end{array}$} & \multirow{2}{*}{$\mathrm{S}_{1}$} & \multirow{3}{*}{$\begin{array}{l}\mathrm{S}_{2} \\
(1,0.9) \\
(1,0.5)\end{array}$} & \multirow{4}{*}{$\begin{array}{l}\mathrm{S}_{3} \\
(1,0.5) \\
(1,0.8) \\
(1,0.7)\end{array}$} \\
\hline & $\mathrm{P}_{1}$ & $\int(0.7,0)$ & $(0.9,0)$ & & & & & & & \\
\hline & $\mathrm{P}_{2}$ & $(0.7,0)$ & $(0.5,0)$ & & & $=$ & & $(1,0.7)$ & & \\
\hline & $\mathrm{P}_{3}$ & $(0.9,0)$ & $(0.6,0)$ & & & & $\mathrm{P}_{3}$ & $(1,0.9)$ & $(1,0.6)$ & \\
\hline
\end{tabular}

\section{SteP3 and step4}

Thus we have

$\tilde{R}_{1}=\tilde{B} \circ \tilde{A} \quad$ and $\quad \tilde{R}_{2}=\tilde{B} \circ \tilde{A}^{\circ}$

$$
\begin{aligned}
& \text { d1 } \quad \text { d2 } \\
& \tilde{R}_{1}=\begin{array}{l}
\mathrm{S}_{1} \\
\mathrm{~S}_{2} \\
\mathrm{~S}_{3}
\end{array}\left[\begin{array}{ll}
(0.49,0) & (0.63,0) \\
(0.49,0) & (0.64,0) \\
(0.63,0) & (0.56,0)
\end{array}\right] \\
& \mathrm{d}_{1} \quad \mathrm{~d}_{2} \\
& \tilde{R}_{2}=\begin{array}{l}
\mathrm{S}_{1} \\
\mathrm{~S}_{2} \\
\mathrm{~S}_{3}
\end{array}\left[\begin{array}{ll}
(0.9,0) & (0.9,0) \\
(0.8,0) & (0.8,0) \\
(0.9,0) & (0.9,0)
\end{array}\right)
\end{aligned}
$$

membership value matrices $M V\left(\tilde{R}_{1}\right)$ and $M V\left(\tilde{R}_{2}\right)$

$$
\begin{aligned}
& \mathrm{d}_{1} \quad \mathrm{~d}_{2}
\end{aligned}
$$

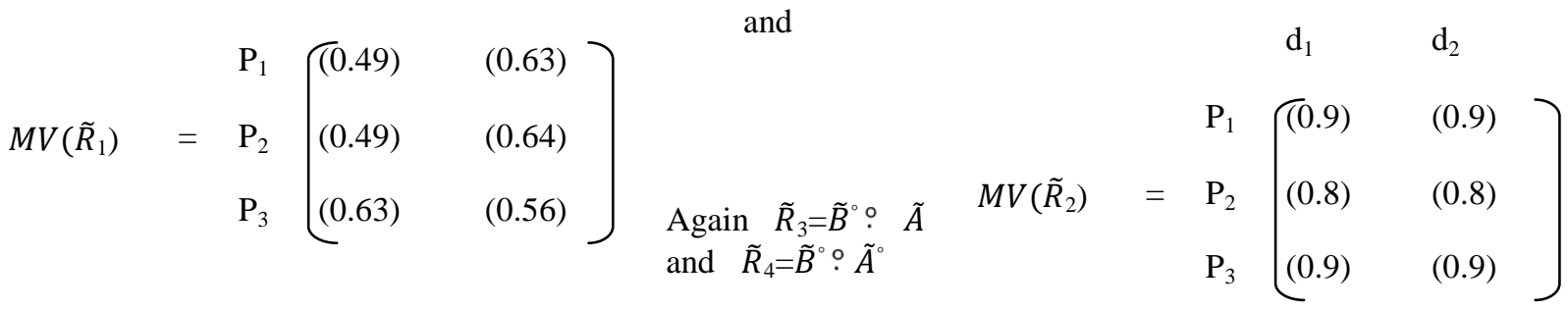

$$
\begin{aligned}
& \begin{array}{lllll}
\mathrm{d}_{1} & \mathrm{~d}_{2} & \mathrm{~d}_{1} & \mathrm{~d}_{2}
\end{array}
\end{aligned}
$$

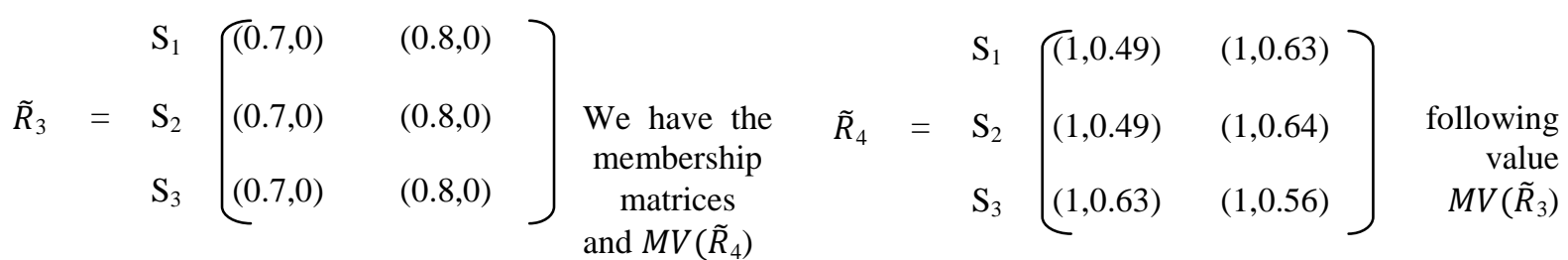

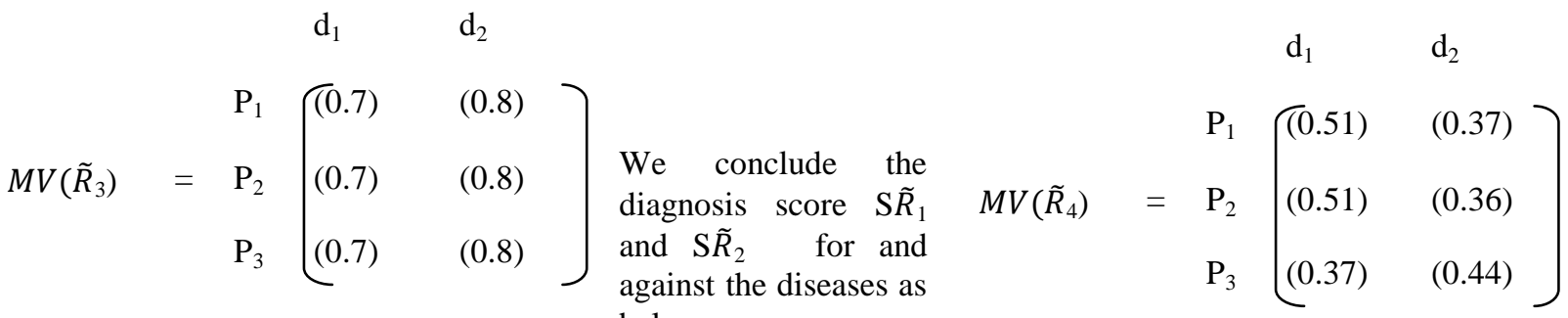

$\mathrm{d}_{1} \quad \mathrm{~d}_{2}$ 
$\mathrm{S} \tilde{R}_{1}=M V\left(\tilde{R}_{3}\right)-M V\left(\tilde{R}_{1}\right)$
$\mathrm{S} \tilde{R}_{2}=M V\left(\tilde{R}_{2}\right)-M V\left(R_{4}\right)$

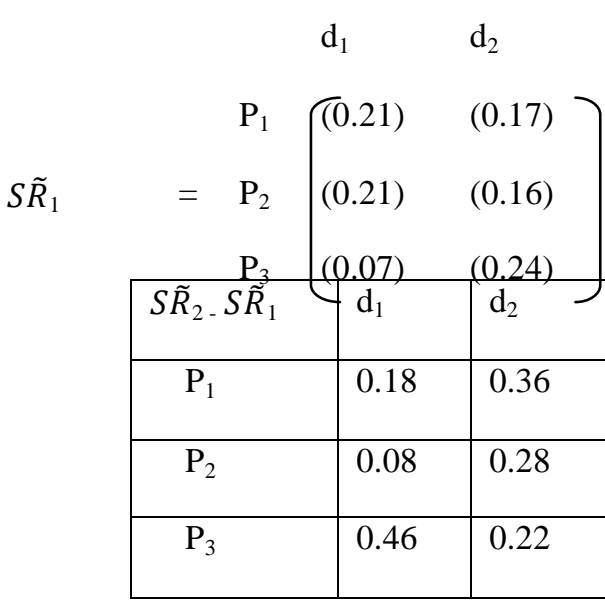

$S \tilde{R}_{2}=\quad \begin{aligned} & \mathrm{P}_{1} \\ & \mathrm{P}_{3}\end{aligned}\left[\begin{array}{ll}(0.39) & (0.53) \\ (0.29) & (0.44) \\ (0.53) & (0.46)\end{array}\right]$

Step5

Now we have the difference for and against the diseases

Fig-Ebola virus in human body

We conclude that is suffering from more serious problem $\mathrm{P}_{1}$ and $\mathrm{P}_{2}$ form the diseases advanced stage of Ebola hemorrhagic fever $(E H F)\left(d_{2}\right) P_{3}$ are suffering from the disease earlier stage of Ebola hemorrhagic fever $(\mathrm{EHF})\left(\mathrm{d}_{1}\right)$.

\section{CONCLUSION}

In this paper, we clarify the theory fuzzy soft matrices in the field of human diseases diagnosis. We improve some new notions such as complement of max product of fuzzy soft matrix based of reference function. At the conclusion, the Ebola virus affected persons should be given conscious of how it has affected the human body. Future work in this regard would be required to study whether the concepts put forward in this paper yield a fruitful result.

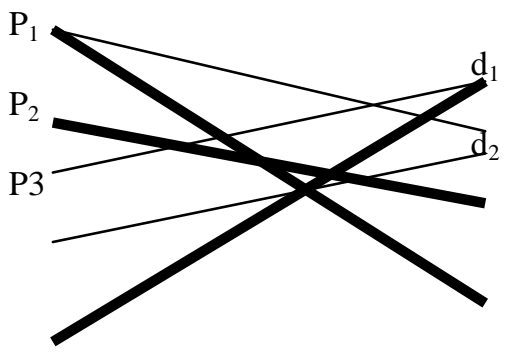

\section{REFERENCES}

[1]. L.A.Zadeh(1965), Fuzzy sets, Information and control,8, pp:338-353.

[2]. D.Molodtsov(1999), Soft set Theory First Results, Computer and Mathematics with applications, 37, pp:19-31.

[3]. P.K.Maji, .R.Biswas and A.R.Roy(2001), Fuzzy Soft Sets, The Journal of fuzzy mathematics, Volume 9, No.3, pp:589-602.

[4]. B.Ahmad and A.Kharal(2009), On Fuzzy Soft Sets, Advances in Fuzzy systems, pp:16.

[5]. A.R.Meenakshi and M.Kaliraja(2011), An application of Interval valued fuzzy matrices in Medical Diagnosis, International Journal of Math. Analysis, Vol.5, No.36,pp: 17911802.

[6]. Wiwanitkit V. Unprecedented scale ebola epidemic in Guinea: what we should know. Asian Pac J Trop Biomed 2014; 4(2): 675.

International Journal of Engineering Research and Applications (IJERA) is UGC approved Journal with Sl. No. 4525, Journal no. 47088. Indexed in Cross Ref, Index Copernicus (ICV 80.82), NASA, Ads, Researcher Id Thomson Reuters, DOAJ.

T. Geetha . "Fuzzy Matrix for Ebola Virus Disease in Human Body." International Journal of Engineering Research and Applications (IJERA) 7.7 (2017): 50-54. 